TITLE:

\title{
MICROSTRUCTURE AND MECHANICAL PROPERTIES OF NITRIDED MOLYBDENUM SILICIDE COATINGS
}

\author{
J-P. Hirvonen, Technical Research Centre of Finland, FIN-02151 Espoo, Finland \\ I. Suni, \\ AUTHORIS): \\ H. Kattelus, \\ Technical Research Centre of Finland, FIN-02151 Espoo, Finland \\ R. Lappalainen, \\ P. Torri, \\ H. Kung, \\ T.R. Jervis, \\ M. Nastasi, \\ Technical Research Centre of Finland, FIN-02151 Espoo, Finland \\ University of Helsinki, FIN-00014 Finland \\ University of Helsinki, FIN-00014 Finland \\ Los Alamos National Laboratory, Los Alamos, NM 87545 \\ Los Alamos National Laboratory, Los Alamos, NM 87545 \\ Los Alamos National Laboratory, Los Alamos, NM 87545
}

SUBMITTED TO:

Materials Research Society Symposium Proceedings, J. J. Petrovic and C. L. Briant, Editors, Materials Research Society, Pittsburgh PA

\section{DISCLAIMER}

This report was prepared as an account of work sponsored by an agency of the United States Government. Neither the United States Government nor any agency thereof, nor any of their employees, makes any warranty, express or implied, or assumes any legal liability or responsibility for the accuracy, completeness, or usefulness of any information, apparatus, product, or process disclosed, or represents that its use would not infringe privately owned rights. Reference herein to any specific commercial product, process, or service by trade name, trademark, manufacturer, or otherwise does not necessarily constitute or imply its endorsement, recommendation, or favoring by the United States Government or any agency thereof. The views and opinions of authors expressed herein do not necessarily state or reflect those of the United States Government or any agency thereof.

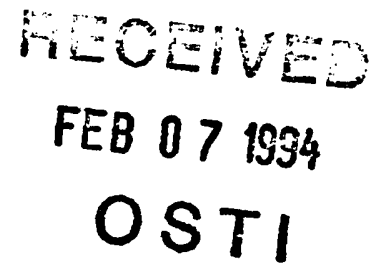

By acceptance of this article. the publisher recognizes that the U.S Government retains a nonexclusive. royalty-iree license to publish or reproduce the published form of this contribution. or to allow others to do so. for U.S Government durposes.

The Los Alamos National Laboratory requests that the publisher identily this article as work performed under the auspices of the U.S. Department of Energy. 


\title{
MICROSTRUCTURE AND MECHANICAL PROPERTIES OF NITRIDED MOLYBDENUM SILICIDE COATINGS.
}

J-P. Hirvonen, I. Suni, and H. Kattelus, Technical Research Centre of Finland, FIN02151 Espoo, Finland; $R$. Lappalainen and P. Torri, FIN-00014 University of Helsinki, Finland, H. Kung, T.R. Jervis, and M. Nastasi, Los Alamos National Laboratory, Los Alamos, NM 87545, USA.

\begin{abstract}
Mo-Si-N films with a high nitrogen concentration were produced by sputter-deposition in the presence of nitrogen plasma. The chemical composition was determined with Rutherford backscattering and nuclear reaction analysis. The ratio of Mo to Si was 1:2 in the coatings with a nitrogen concentration of $50 \%$. The microstructure of the as-deposited coatings on a silicon substrate was amorphous and no crystallization was found after annealing up to $1000{ }^{\circ} \mathrm{C}$, although some relaxation was observed in X-ray diffraction. This was confirmed in highresolution transmission electron microscope examination. The hardness of the Mo-Si-N films was $18.8 \mathrm{GPa}$ as determined with a nanoindenter. This is significantly higher than that of $\mathrm{MoSi}_{2}$ films, 11.2 GPa. The hardness of the Mo-Si-N films increased to $24.4 \mathrm{GPa}$ after annealing at $800{ }^{\circ} \mathrm{C}$, which is approximately the same as the hardness of the high-temperature tetragonal phase of $\mathrm{MoSi}_{2}, 25.5 \mathrm{GPa}$. Similarly, the modulus of the as-deposited Mo-Si-N film was higher $(257 \mathrm{GPa}$ ) than that of the MoSi2 film (222 GPa). However, only a slight increase in the modulus of the Mo-Si-N film was found after annealing at $800^{\circ} \mathrm{C}$, whereas the modulus of the crystallized tetragonal MoSi2 was $382 \mathrm{GPa}$. No cracking was found in the Mo-Si-N films even after annealing at $1000^{\circ} \mathrm{C}$.
\end{abstract}

\section{INTRODUCTION}

The excellent oxidation resistance of molybdenum disilicide $\left(\mathrm{MoSi}_{2}\right)$ is widely known, as is its lack of ductility at low temperatures [1]. This disadvantage restricts the extensive use of $\mathrm{MoSi}_{2}$ as a structural material. When applied as a coating, a more ductile base material can be used, and in this way the problem may be partly avoided. However, thermal stresses due to a nismatch of thermal expansion coefficients may result in cracking which will eventually degrade the good protective properties. In addition, possible transformation stresses in a coating can also result in cracking.

Reinforcement with particulates or fibers, such as $\mathrm{TiB}_{2}, \mathrm{Al}_{2} \mathrm{O}_{3}$, and $\mathrm{SiC}[2,3]$, or combination with a ductile phase such as tantalum [4] have been used to reduce the lowtemperature brittleness of $\mathrm{MoSi}_{2}$. In these cases, at best an improvement in the fracture toughness from 2.7 to $4.9 \mathrm{MPa} / \mathrm{m}^{1 / 2}$ was reported [4]. Recently a new approach, refinement of the microstructure down to the nanometer scale, has been used to enhance the mechanical performance of materials. In our previous work, we have reported the deposition and characterization of $\mathrm{MoSi}_{2} / \mathrm{SiC}$ composite coatings [5]. Layered nanostructures were produced by sputter deposition. The main purpose of the SiC layers was to prevent a crystal growth of $\mathrm{MoSi}_{2}$. Silicon carbide was chosen as a constituent because of the thermodynamic stability of a $\mathrm{MoSi}_{2} / \mathrm{SiC}$ pair [6]. However, no improvement in room temperature toughness was observed, although indentation fracture measurements indicated different fracture behavior when compared to that of a single $\mathrm{MoSi}_{2}$ layer.

Cracking of the $\mathrm{MoSi}_{2} / \mathrm{SiC}$ composite coatings was, however, reduced during oxidation at relatively low temperatures. In fact a reduction of $66 \%$ in the crack line density was observed as compared to the cracking of a single $\mathrm{MoSi}_{2}$ coating with approximately identical thickness. The 
composite coating still possessed good oxidation resistance, but differences were detected in the oxidation mechanism [7].

Previous experience suggests the possibility of cracking can be reduced by improving the ductility of the coating, by attaining an enhanced compatibility of elastic and thermal expansion properties between the base material and the coating, or by avoiding phase transformations. In this work we have successfully applied mcst of these principles by producing amorphous molybdenum silicide with a significantly higher crystallization temperature than usual. This was obtained by nitrogen alloying simultaneously during the sputter deposition.

\section{EXPERIMENTAL PROCEDURE AND MEASUREMENTS}

Single crystal silicon wafers and unalloyed carbon steel were employed as substrates. Prior to deposition the steel samples were mechanically polished, degreased in TCE, acetone and isopropanol, and finally sputter cleaned. A 1:50 HF: $\mathrm{H}_{2} \mathrm{O}$ solution was used to remove the native oxide of the silicon wafers. Dedositions on the silicon substrates were used to determine the chemical composition of the coatings (using Rutherford backscattering (RBS) spectroscopy and th. $429 \mathrm{KeV}$ resonance of the reaction ${ }^{15} \mathrm{~N}(p, \alpha-\gamma)^{12} \mathrm{C}$ [8] (NRA)), in nanoindentation measurements, in transmission electron microscopy (TEM), and in $x$-ray diffiction (XRD) examinations. Oxidation, corrosion, and thermal cracking measurements were performed on the steel samples. In this paper we report on the results obtained concerning the coatings on the silicon substrates.

Sputter deposition was carried out at a pressure of $1 \mathrm{~Pa}$ with an argon and nitrogen flow of $10 \mathrm{sccm} / \mathrm{min}$. The nitrogen gas concentration in the flow was $50 \%$. Prior to deposition the chamber was evacuated down to a pressure of $10^{-4} \mathrm{~Pa}$. Molybdenum silicide was sputtered from a planar magnetron $\mathrm{MoSi}_{2}$ target with a diameter of $100 \mathrm{~mm}$ at a $\mathrm{DC}$ power of $200 \mathrm{~W}$. The deposition rate was $27 \mathrm{~nm} / \mathrm{min}$. MoSi2 coatings without nitrogen were alsc deposited onto the same substrate materials for reference. The thickness of the coatings varied from $1.2 \mu \mathrm{m}$ to more than $3 \mu \mathrm{m}$.

In order to investigate the effect of heat treatment on the microstructure, the hardness and elastic properties, and the cracking of the coatings, annealing was performed in a quartz tube furnace at a temperature range of $450-1000^{\circ} \mathrm{C}$. Both the as-sputtered and annealed $(1 \mathrm{~h}$ at 800 $\left.{ }^{\circ} \mathrm{C}\right) \mathrm{Mo}-\mathrm{Si}-\mathrm{N}$ coatings were made into cross-section TEM (XTEM) specimens using M-bond 610 for structural characterization. The specimens were examined using conventional and highresolution transmission electron microscopy (HRTEM) on a Phillips CM30ST microscope operating at $300 \mathrm{kV}$. Thermal cracking was examined with a scanning electron microscope (SEM). The hardness and elastic properties were determined with a commercially available nanoindentation instrument.

\section{RESULTS AND DISCUSSION}

In Fig. 1 RBS spectra from as-deposited Mo-Si-N films are shown. The molybdenum to silicon ratio corresponds well to that of the sputtering target, $[\mathrm{Mo}]:[\mathrm{Si}]=1: 2$. The nitrogen concentration, determined from NRA, was 50 at. $\%$ and the concentration profile very uniform, as can also be seen in Fig. 1.

An isothermal section of the Mo-Si-N ternary phase diagram at $1400{ }^{\circ} \mathrm{C}$ is given in reference [9]. In the Mo-Si-N system silicon nitride $\mathrm{Si}_{3} \mathrm{~N}_{4}$ can coexist with both $\mathrm{MoSi}_{2}$ and $\mathrm{MoSi}_{3}$ but no molybdenum nitride is stable without excess nitrogen at temperatures above 1000 ${ }^{\circ} \mathrm{C}$. The third silicide of the Mo-Si system is $\mathrm{Mo}_{3} \mathrm{Si}$. Nitrogen is considered as practically insoluble in MoSi2. The composition of our coatings is located quite close to silicon nitride 
$\left(\mathrm{Si}_{3} \mathrm{~N}_{4}\right)$ on the isothermal section of the Mo-Si-N phase diagram. In fact, in ESCA measurements, a strong chemical interaction between silicon and nitrogen was observed, whereas in the $\mathrm{MoSi}_{2}$ films the only bond type was the silicide type between silicon and molybdenum. It should be noted that chemical interaction between silicon and nitrogen is much stronger (heat of formation $-25.6 \mathrm{kcal} / \mathrm{g}$-at. [10]) than that between silicon and molybdenum (heat of formation-9.3, -8.5 , and $-5.8 \mathrm{Kcal} / \mathrm{g}$-at for $\mathrm{MoSi}_{2}, \mathrm{Mo}_{5} \mathrm{Si}_{3}$, and $\mathrm{Mo}_{3} \mathrm{Si}$ respectively $[11 !]$
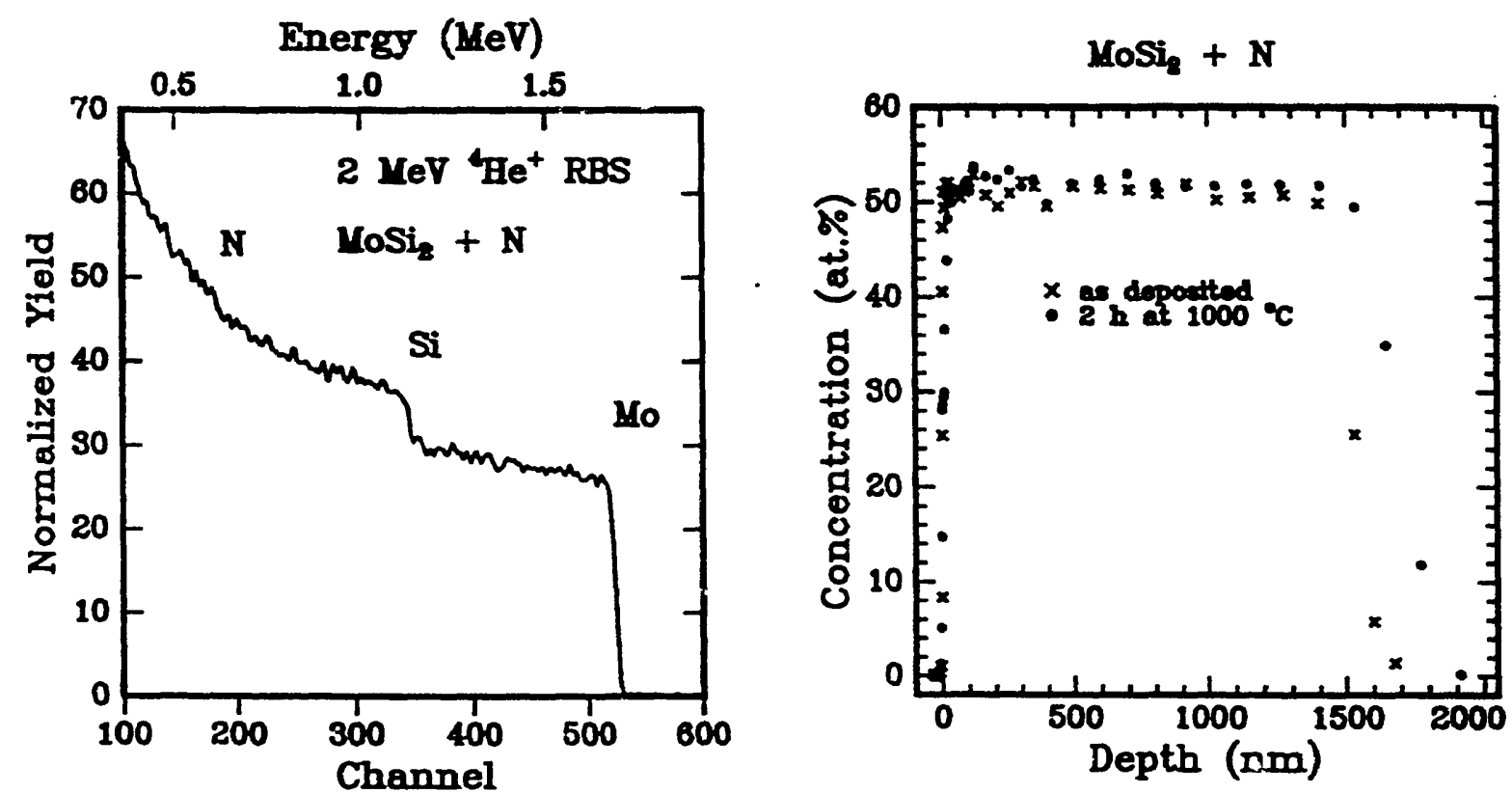

Fig. 1. RBS spectrum and nizogen distribution of the Mo-Si-N coating.

The microstructure of both the as-deposited $\mathrm{MoSi}_{2}$ and $\mathrm{Mo}-\mathrm{Si}-\mathrm{N}$ films was amorphous as determined by XRD. After annealing at $500^{\circ} \mathrm{C}$ in a vacuum furnace, $\mathrm{MoSi}_{2}$ films crystallize to a hexagonal structure, which is the stable phase of molybdenum disilicide at low temperatures. Nitrided Mo-Si-N fiims are still amorphous after annealing, as indicated by the broad diffuse feature in the spectrum. Even after annealing at $1000^{\circ} \mathrm{C}$ the microstructure of these films remains amorphous. However, changes in the shape of the amorphous feature of the Mo-Si-N after annealing at high temperatures can be observed, which relate to a relaxation of the structure. This was also confirmed by TEM results. HRTEM observation of the as-deposited films revealed the amorphous structure as shown in Fig. 2(a). Fig. 2(b) shows the corresponding selected area diffraction (SAD) pattern. The diffuse rings indicate the presence of an amorphous structure which is consistent with the observation in (a). By measuring the diameter of the innermost ring and converted to the real space spacing using the known camera constant, the nearest neighbor distance was estimated to be $2.30 \AA$.

As discussed above, annealing the $\mathrm{Mo}-\mathrm{Si}-\mathrm{N}$ films at $800^{\circ} \mathrm{C}$ for $1 \mathrm{~h}$ failed to crystaliize the amorphous stricture, as shown in Fig. 3(a). Fig. 3(b) shows the corresponding SAD pattern which confirms the amorphous nature of the structure. Even though Fig. 3 shows the amorphous structure, careful examination of the two structures reveals the difference in their detailed microstructure. Afte- the $800^{\circ} \mathrm{C}$ anneal, the amorphous structure seems to have a coarser microstructure and a different nearest neighbor spacing than the as-sputtered film. The latter difference is confirmed by comparing the diameters of the innermost ring on the SAD patterns. The ring diameter of the annealed film is $2.5 \%$ larger than the as-sputtered one, and corresponds to a nearest neighbor spacing of $2.25 \AA$. The decrease in the nearest neighbor spacing from 2.30 to $2.25 \AA$ suggests that the annealing may have reduced the free volume in the as sputtered films and caused the densification of the coatings. 

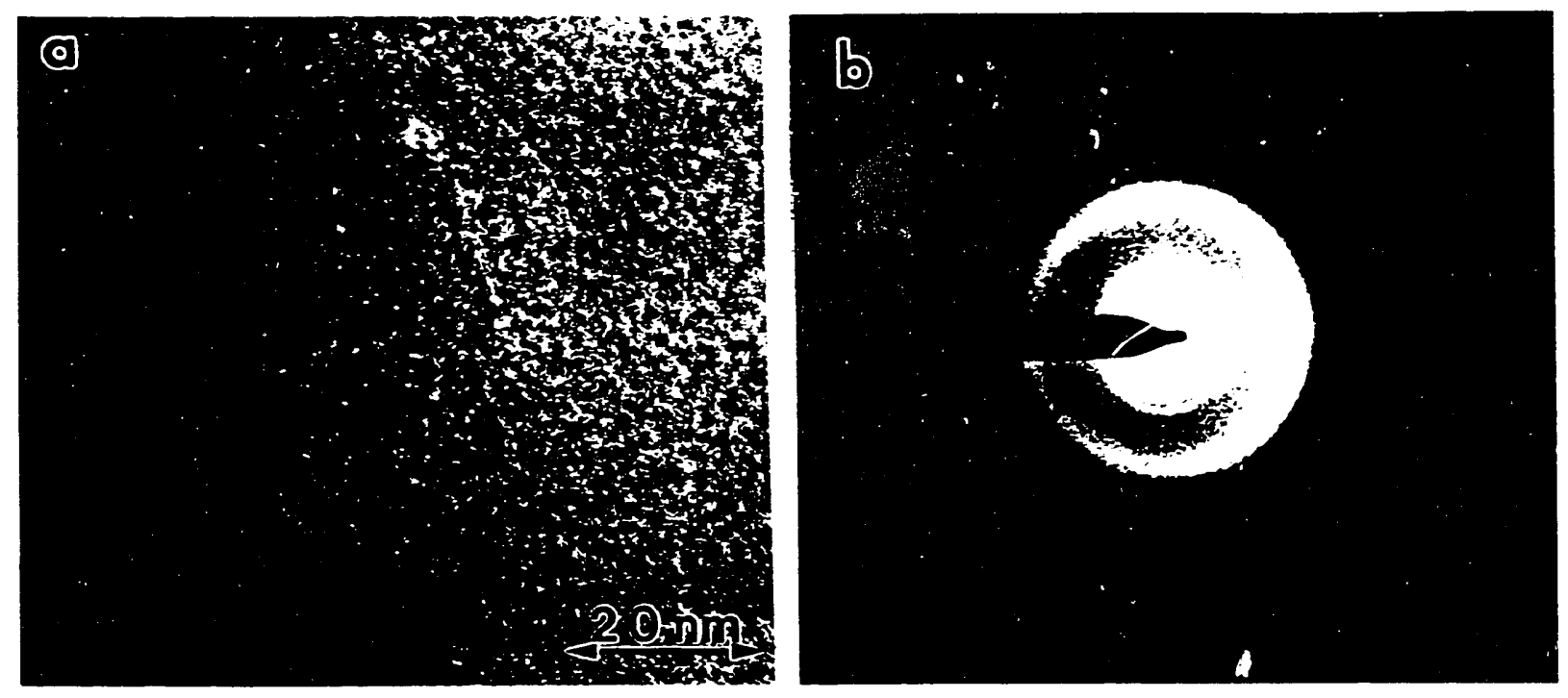

Fig. 2. (a) Cross-section TEM micrograph of an as-deposited Mo-Si-N coating.

(b) Corresponding $S A D$ pattern.
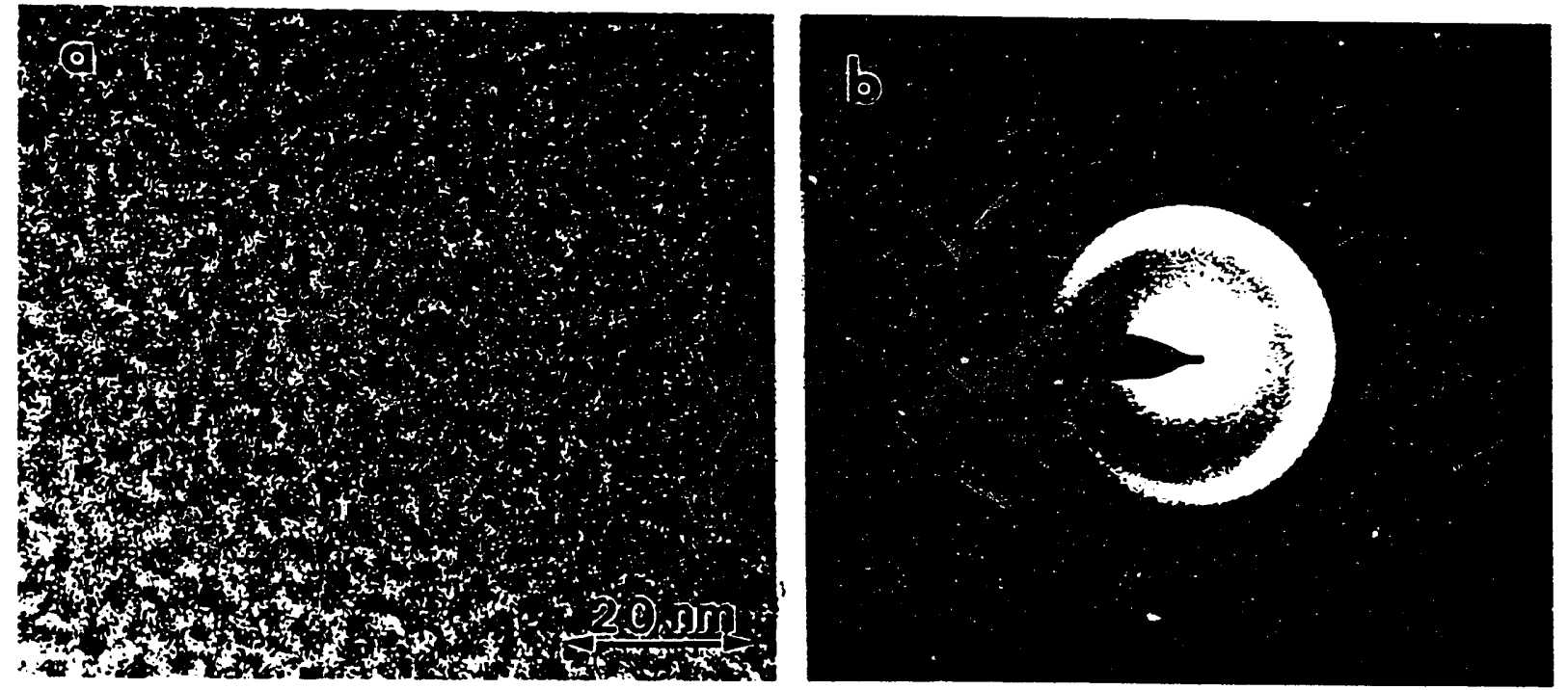

Fig. 3. (a) Cross-section TEM micrograph of the Mo-Si-N coating annealed at $800{ }^{\circ} \mathrm{C}$ for $1 \mathrm{~h}$ (b) Corresponding $S A D$ pattern.

In Table 1, the mechanical properties of the as-deposited and heat treated Mo-Si-N films are shown. For comparison, the modulus and hardness of $\mathrm{MoSi}_{2}$ films with different microstructures are given. The modulus of the as-deposited $\mathrm{Mo}-\mathrm{Si}-\mathrm{N}$ films is somewhat higher than that of the as-deposited $\mathrm{MoSi}_{2}$ films. However, tetragonal $\mathrm{MoSi}_{2}$ films have a significantly higher modulus, $382 \mathrm{GPa}$, reflecting the transformation to a crystalline phase. The fact that the modulus of the Mo-Si-N films remains fairly low may result in much lower residual and thermal stresses in these films. The value of the modulus of the Mo-Si-N coatings is, in fact, quite close to that of the most common steels, about $210 \mathrm{GPa}$. 
Table 1. Mechanical properties of Mo-Si-N and $\mathrm{MoSi}_{2}$ thin films.

\begin{tabular}{lcc}
\hline \hline Sample & Modulus [GPa] & Hardness [GPa] \\
\hline As-deposited Mo-Si-N (amorphous) & 257 & 18.8 \\
Annealed 1 h @800 ${ }^{\circ} \mathrm{C}$ (amorphous) & 273 & 24.4 \\
As-deposited MoSi2 (amorphous) & 222 & 11.2 \\
Annealed 1 h @500 & \\
Annealed 1 h @ $900^{\circ} \mathrm{C}$ (texagonal) & 278 & 22.0 \\
\end{tabular}

Indentation measurements show that after annealing at $800^{\circ} \mathrm{C}$, the hardness of the Mo$\mathrm{Si}-\mathrm{N}$ films has increased from 18.8 to $24.4 \mathrm{GPa}$, while little difference in modulus was observed. The increase in hardness could be the result of the densification process discussed above. In any case, the hardness of the Mo-Si-N films is much higher than that of the amorphous $\mathrm{MoSi}_{2}$ films. However, since no crystallization process is involved, one would not expect the elastic properties of the materials to change much, which is consistent with the small change in modulus observed in this case.

Thermal cracking was examined by annealing the samples at different temperatures in vacuum and viewing the possible cracking in a scanning electron microscope. In Fig. 4 SEM micrographs of the samples annealed at different temperatures are shown. Cracking is seen in the $\mathrm{MoSi}_{2}$ coatings even after annealing at relatively low temperatures. In contrast, no cracking is observed on the Mo-Si-N cuatings, even after annealing at $1000{ }^{\circ} \mathrm{C}$. This absence of cracking may be due to several reasons. The modulus of the Mo-Si-N coating is closer to that of the substrate. There is no phase transformation (wnich could cause transformation stresses) in the temperature range investigated. Finally, the fracture toughness of amorphous material may be higher than that of crystalli. e material, although no direct evidence of this was obtained in the current experiments. This resistance to thermal cracking makes Mo-Si-N coatings very attractive for protective coatings in corrosive and hostile environments at elevated temperatures.

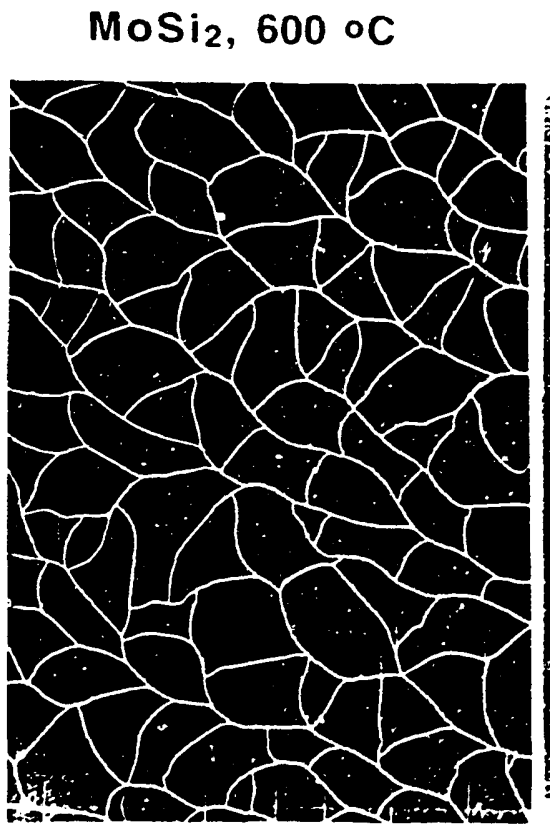

Mo-Si-N, 600 oC

Mo-Si-N, 1000 oC
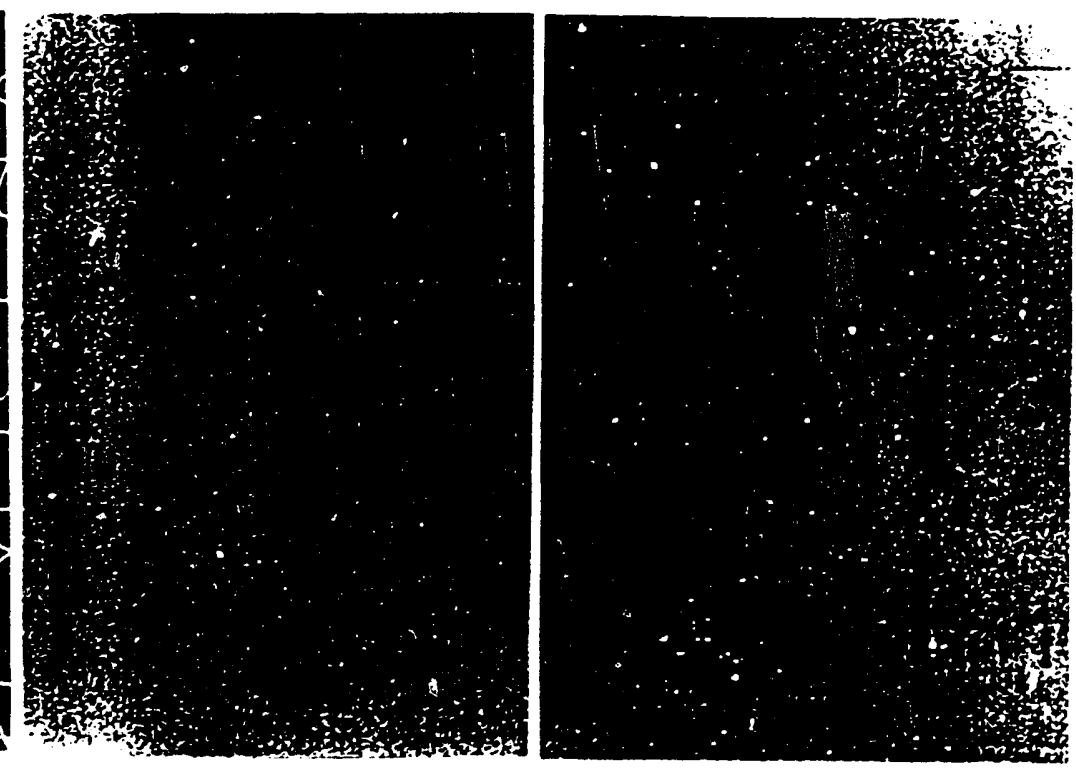

$50 \quad 11 \mathrm{~m}$

Fig. 4. SEM micrographs of MoSiz coating annealed at $600{ }^{\circ} \mathrm{C}$ and Mo-Si-N coatings annealed at 600 and $1000{ }^{\circ} \mathrm{C}$. 


\section{CONCLUSIONS}

Based on our observations, we can conclude that: i) molybdenum-silicon films with high nitrogen concentrations can be deposited by DC sputtering in the presence of a nitrogen plasma, ii) nitrogen significantly increases the crystallization temperature of molybdenum-silicon films, iii) the hardness and modulus of $\mathrm{Mo}-\mathrm{Si}-\mathrm{N}$ films are higher than those of amorphous $\mathrm{MoSi}_{2}$ films; (after recrystallization into a tetragonal structure, the modulus of $\mathrm{MoSi}_{2}$ films is greater than that of amorphous Mo-Si-N films), iv) thermal cracking of Mo-Si-N films is almost completely prevented at temperatures below $1000^{\circ} \mathrm{C}$.

\section{ACKNOWLEDGMENTS}

This wark at the Metallurgy Laboratory of the Technical Research Centre of Finland (VTT) is supported jointly by The Academy of Finland and VTT through the project on "Nanocrystalline Thin Films and Multilayered Structures", and at the Los Aiamos National Laboratory by the Department of Energy, Office of Basic Energy Science, Division of Advanced Energy Projects.

\section{REFERENCES}

[1] J. Schlichting, High Temperatures - High Pressures 10241 (1978).

[2] P.J. Meschter, Scriptn Met. 251065 (1991).

[3] C.H. Henager, J.L. Brinhall, and J.P. Hirth, Scripta Met. 26585 (1992).

[4] R.G. Castro, R.W. Smith, A.D. Rol!ett, and P.W. Stanek, Scripta Met. 26207 (1992).

[5] J-P. Hirvonen, H. Kattelus, I. Suni, J. Likonen, T.R. Jervis, and M. Nast si, in $^{2}$ Mechanical Properties and Deformation Behavior of Materials Having Ultra-Fine Microstructure, eds. M. Nastasi et. al. (Kluwer Academic Publishers, the Netherlands, 1993) p. 469.

[6] H.J. Goldschmidt, Interstitial Alloys (Butterworth and Co., Great Britain, 1967) p 560.

[7] J-P. Hirvonen, R. Lappalainen, H. Kattelus, J. Likonen, I. Suni, H. Kung, T.R. Jervis, and M. Nastasi, Mat. Res. Soc. Symp. Soc. 286373 (1993).

[8] R. Lappalainen, Phys. Rev. B34 3076 (1986).

[9] Phase Diagrams of Ternary Boron Nitride and Silicon Nitride Systems, eds. P. Rogl and J.C. Schuster (ASM International, Materials Park, OH, 1992) p. 169.

[10] CRC Handbook of Chemistry and Physics, 63rd edition (CRC Press, Boca Raton, FL, 1984).

[11] M-A. Nicolct and S.S. Lau, in VLSI Electronics: Microstructures Science ed. by N. G. Einspruch, Vol. 6 (Academic Press, Orlando FL, 1983) p. 330. 


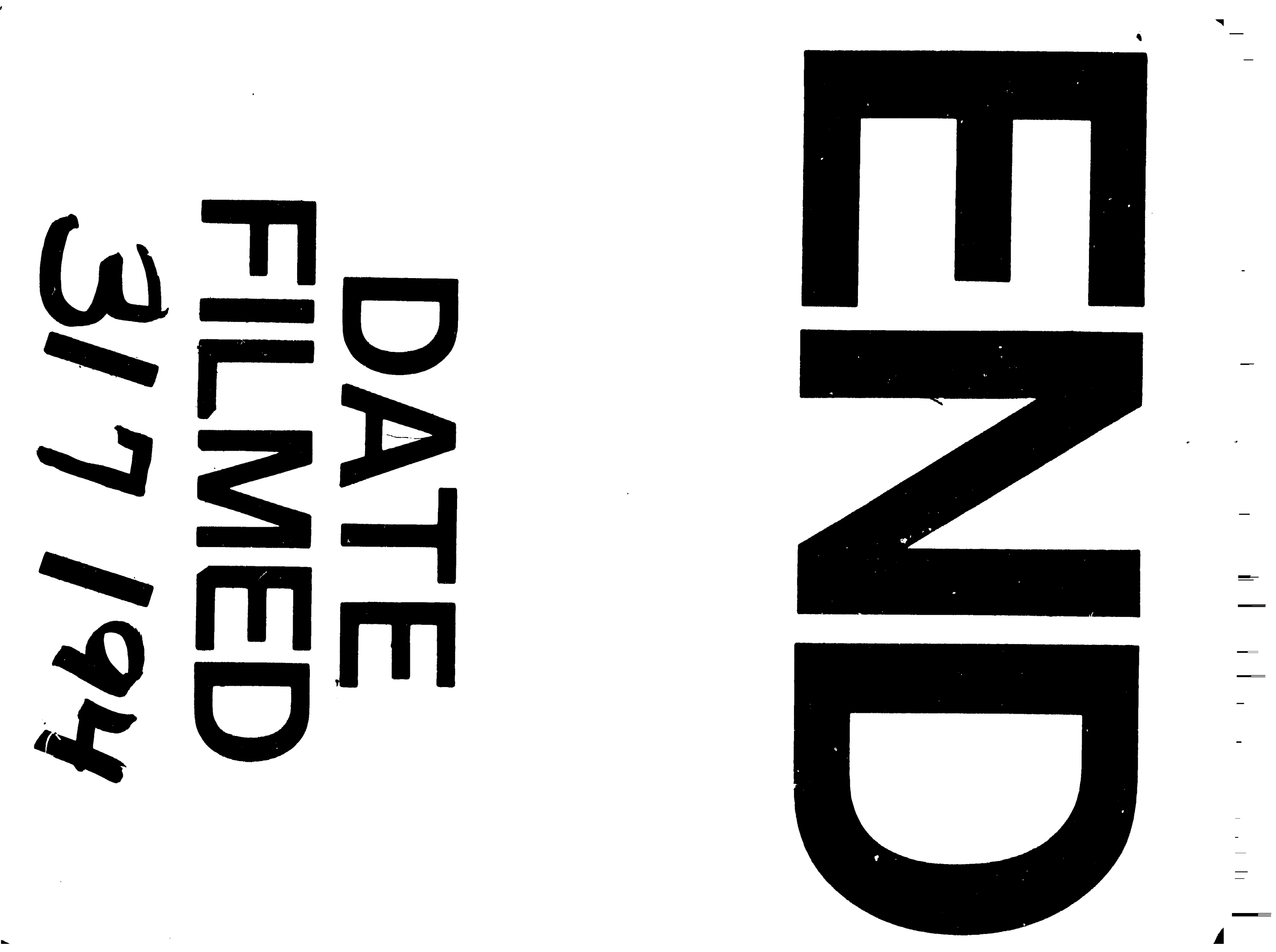

